\title{
Just some order in financial reporting studies... the need for a taxonomy
}

Alberto Quagli

The pressure for publishing, together with the global scope of financial reporting research, contribute to an impressive production of original studies by scholars, with no more geographical borders. Obviously this fact is positive for the progress of our discipline but if we get a keener look at the situation, we can identify many aspects where a more collaborative activity within the community of scholars could improve our work, giving more order to our field of study.

In this sense, an urgent need is the development of a taxonomy of issues. A taxonomy refers to the unavoidable necessity to classify studies (articles, books, and other contributions), in order to easy search and retrieval. For a researcher a clear understanding of previous studies on the same issue is a due step of the work, but this activity is often based on heuristics, with a large potential to increase its efficiency. The actual research strategies are different. One of the most used is starting from some well-known papers, and, through the references included there, enlarging the knowledge of the extant literature. More systematic research in scientific paper data-bases is often the following step, but we need to choose the right keywords, in order not to miss relevant work. Obviously, with a detailed and generally accepted taxonomy applied on all the papers, this searching activity would be enormously empowered. In this sense, the impressive growth of scientific journals and other publications contributes to increasing the problem and the necessity for its solution.

We don't have any general accepted taxonomy in our field. The only ones available are too broad to work as useful tools for searching. For example, the European Accounting Association traditionally uses the following classification: Auditing, Accounting Education, Financial Analysis, Financial Reporting, Accounting and Governance, Accounting and Infor- 
mation Systems, Management Accounting, Public Sector Accounting, Social and Environmental Accounting, Taxation. The borders between the different categories are clear but there is a strong need for a more detailed classification at a second level. For example, inside the category "Financial Reporting" we can have studies on narrative disclosure, on market reaction to different accounting information, on the standard setting process and so on. The classification used by the American Accounting Association is similar, even if other specific domains are introduced (Accounting Behavior and Organizations, Accounting History, Forensic and Investigative Accounting, Gender Issues and Worklife Balance, International Accounting, Strategic and Emerging Technologies).

At the moment, a real debate on accounting taxonomy is lacking. There is some work on taxonomy, but this concerns only methodology. According to this taxonomy, papers are classified as: archival, experiment, case study, review, survey, theoretical, empirical, normative and so on (for a review and a proposal see Olalere, 2011). Methodology is important, but there is a need for classifying the content as well. We are aware that contents are continuously changing: new approaches, new perspectives emerge, so that the process of classifying will never end. Multiple segmentation criteria could be used simultaneously. Just one example: to classify the content of an empirical study that uses archival data and aims at demonstrating if corporate governance variables are significant drivers of earnings management in goodwill impairment test under IAS 36, we could choose various levels of "accounting scenario" (before IFRS, then IAS 36), of "accounting object" (before goodwill then impairment test), of explanatory variables and hypotheses (before corporate governance, then the specific proxies), of sample used (what companies, what observation period), and so on.

The issue is very complex and would probably deserve a much more specific articulation and speculation. But we imagine that readers can perceive the relevance of a taxonomy. The progress of many sciences is based on taxonomy. We, as financial reporting scholars, do not have anything like that.

Who can develop this taxonomy? I have serious doubts about the possibility of a generally accepted taxonomy coming from individual scholars or small groups. Only a strong association or a large cooperation in the scientific community could succeed. It requires a specific project, a due process of drafts and consultations, as every standard creation activity requires. On my side, I will try to foster the sensibility to this problem. If no one stronger will take action, we can try. But first the stronger ones. 